\title{
Visual Activity in Hollywood Film: 1935 to 2005 and Beyond
}

\author{
James E. Cutting, Jordan E. DeLong, and Kaitlin L. Brunick \\ Cornell University
}

\begin{abstract}
The structure of Hollywood film has changed in many ways over the last 75 years, and much of that change has served to increase the engagement of viewers' perceptual and cognitive processes. We report a new physical measure for cinema - the visual activity index (VAI) - that reflects one of these changes. This index captures the amount of motion and movement in film. We define whole-film VAI as $(1-$ median $r)$, reflecting the median correlation of pixels in pairs of near-adjacent frames measured along the entire length of a film or film sequence. Analyses of 150 films show an increase in VAI from 1935 to 2005, with action and adventure films leading the way and with dramas showing little increase. Using these data and those from three more recent high-intensity films, we explore a possible perceptual and cognitive constraint on popular film: VAI as a function of the log of sequence or film duration. We find that many "queasicam" sequences, those shot with an unsteady camera, often exceed our proposed constraint.
\end{abstract}

Keywords: film, motion, movement, frames, shots

Supplemental materials: http://dx.doi.org/10.1037/a0020995.supp

For many of us, today's popular American cinema is always fast, seldom cheap, and usually out of control. What comes to mind are endless remakes, gross-out comedies, overwhelming special effects, and gigantic explosions with the hero hurtling at the camera just ahead of a fireball. (Bordwell, 2002, p. 16)

After this entrée Bordwell (2002) outlined and documented four changes in popular film since about 1960, roughly the end of the Hollywood era dominated by the film studios (Bordwell, Staiger, \& Thompson, 1985). These changes concern the structure and nature of shots. Shots are continuous runs of successive frames from the film camera separated by transitions. In contemporary cinema almost $99 \%$ of all transitions are cuts-abrupt changes in the flow of the film where the camera changes position. Dissolves, fades, wipes, and other transitions, although common to films before the 1960s, are now quite rare. Shots are designed to capture the viewer's attention and control eye movements (Dmytryk, 1984; Ondaatje, 2004), and they do this quite well (Hasson, Landesman, Knappmeyer, Vallines, Rubin, \& Heeger, 2008; Hasson, Nir, Levy, Fuhrmann, \& Malach, 2004; Smith, 2006; Smith \& Henderson, 2008).

The first change noted by Bordwell (2002), and by many others, concerns a progression toward shorter shot lengths. Shorter shots clearly help rivet attention to the narrative and heighten the emotional response of viewers. Bordwell listed a number of contem-

James E. Cutting, Jordan E. DeLong, and Kaitlin L. Brunick, Department of Psychology, Cornell University.

Portions of the material reported here were part of a keynote address at the 8th conference of the Society for the Cognitive Studies of the Moving Image, Roanoke, VA, June 2-5, 2010.

Correspondence concerning this article should be addressed to James E. Cutting, Department of Psychology, Uris Hall, Cornell University, Ithaca, NY 14853-7601. E-mail: jec7@cornell.edu porary films with average shot lengths (ASL) in the range of 2.5 to $4 \mathrm{~s}$, and he later listed some with even shorter ASLs (Bordwell, 2006, 2007). Nonetheless, the largest pool of normative data comes from Salt (1992, 2006), who measured over 13,000 films released across the 20th century. Grouped mean ASLs for those films are plotted in Figure 1.

Four trends seem evident in Salt's data. First, shot length in silent film declined to about $5 \mathrm{~s}$ just prior to the advent of sound film. Second, the first few years after 1927 created chaos, with ASLs burgeoning to about $12 \mathrm{~s}$ as filmmakers grappled with the new audiovisual medium. Third, throughout most of the classical Hollywood era ASLs bounced around, sometimes turbulently, in the domain of $8 \mathrm{~s}$ as filmmakers mastered musicals, comedies, adaptations of novels, and created film noir. Finally, after the studio era and from about 1960 onward, ASLs declined and again approached $5 \mathrm{~s}$ by the end of the 1990s. Industry-wide ASLs are still declining, but it took 70 years for audiovisual cinema to recapture at least one property that a purely visual cinema had long before.

Diminishing ASLs, however, are not the only change in popular film that concerns shots. We analyzed patterns of shot lengths in Hollywood films from 1935 to 2005 using time-series and power analyses (Cutting, DeLong, \& Nothelfer, 2010). Our results revealed multiscale asynchronous shot rhythms - differential waves of shorter and longer shots progressing along the entire length of a film. Importantly, these fluctuations have begun to match the waves of attention that can be measured in normal adult humans under laboratory conditions (see, e.g., Gilden, 2001; Gilden, Thornton, \& Mallon, 1995; Pressing \& Jolley-Rogers, 1997; Van Orden, Holden, \& Turvey, 2003; Thornton \& Gilden, 2005). Such patterns in film are not due to shorter ASLs, since this factor was removed from the analysis. Instead, we suggested that postclassical Hollywood films are gradually developing shot patterns that mimic the attention patterns endogenous in our minds. Like gen- 


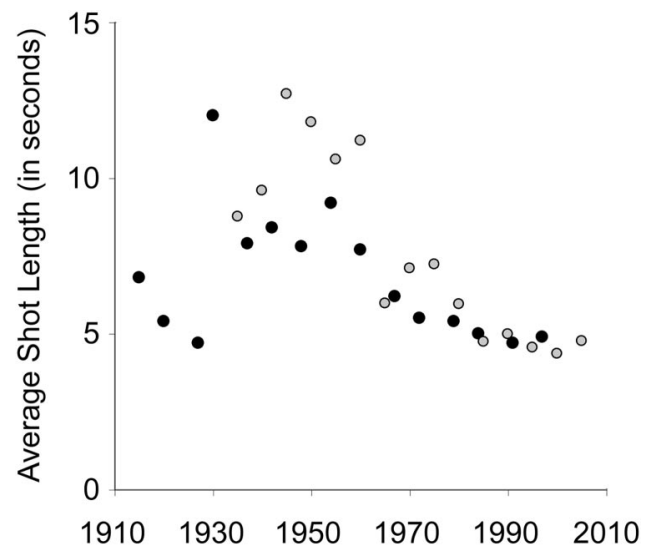

Figure 1. A plot of the grouped mean average shot lengths (ASLs) of more than 13,000 films from Salt $(1992,2006)$ shown as black dots; and the grouped mean ASLs for 150 films from the sample discussed in this article, shown as dots with gray centers.

erally shorter shot lengths, this fluctuation of shots may also serve to make films more engrossing.

Bordwell (2002pp. 121, 2006, pp. 121-138) noted three other changes in more recent films: (a) the use of a wider range of lens lengths yielding more telephoto shots, (b) the increased use of close-ups, particularly in dialog sequences (see also Salt, 2006), and (c) shots from increasingly mobile cameras. These three are of interest to us here because they systematically generate greater visual change in the framed image. That is, telephoto shots enlarge details of people, close-ups make faces and body parts larger, and together they create larger facial and body motions. In addition, smaller and more mobile cameras create more movement across the entire image.

\section{Visual Activity $=$ Motion + Movement}

Many scholars have studied cultural periods by analyzing the films of that era (e.g., Storey, 2009), and a few have studied statistical aspects of films and their contexts (e.g., Simonton, 2002, 2007, 2009). We wholeheartedly endorse both methods. Nonetheless, within these approaches we have taken a different tack. Instead of studying the content or context of film, we focus on their changing physical characteristics as they elucidate our perceptual and cognitive capacities and tolerances. This approach is often called cinemetrics (e.g., http://www.cinemetrics.lv/). In this article we document the amount, and the change in that amount, of motion and movement in cinema.

The two terms are intertwined. Gibson (1954) defined them this way: motion is the change in position of objects and people with respect to a constant background. In cinematic terms, then, this is the change in position of actors and objects within a stationary frame. Movement, on the other hand, is the visual information generated by a moving observer. Thus, in film, movement is the set of changes due to camera motion and lens change-pans, dollies, tilts, cranes, zooms, and their combinations. Without differentiating them, we will call motion and movement by the collective term visual activity. Thus, sound aside, visual activity is what distinguishes movies from photographs.
It is difficult to know how much of the visual activity in film is due to actor and object motion versus camera movement. Nonetheless, we can make a rough estimate. Salt (2006, p. 338) counted the number of shots with camera movements and lens changes in 21 films that appeared in 1999. The median was 92. As part of a larger project (e.g., Cutting et al., 2010), we tallied the total number of shots in 10 films from the year 2000. The median was 1,458 . If one can compare the two samples and reasonably generalize, $92 / 1,458$ or only about $6 \%$ of all shots in turn-of-the-century films may have involved camera action. Given that cameramovement shots create much more image change than do the typical motions of actors, more visual activity than this is due to camera changes - an idea we will document later when discussing several contemporary films. Regardless, the vast majority of visual activity in most films is clearly due to motion, not to movement.

The introductory quotation from Bordwell (2002) might suggest that popular film after the late 1990s had suddenly become ferociously more active. Instead, however, we will demonstrate that normative change has been gradual over the course of the history of sound film. As an elaboration of Bordwell's larger thesis, we will suggest that film has incrementally intensified over 70 years. Our particular goal is straightforward: we want to go beyond measuring ASLs and beyond cataloging actor versus camera movements within them. Indeed, we want to index how much combined motion and movement is projected in film and whether by that measure films have changed over time. This index, then, reflects the visual and some of the cognitive demands that popular films place on viewers. After establishing the changes in films across 70 years, we will investigate three contemporary films that would seem to press against capacities of visual cognition.

\section{Films and Film Processing}

Overall, we are interested in the mesh between popular film and human perceptual and cognitive systems. To this end, we have been measuring various physical aspects of cinema in a sample of 150 films (e.g., Cutting et al., 2010). All follow Hollywood style (e.g., Bordwell et al., 1985; Thompson, 1999), also called invisible style (Messaris, 1994). This goal of this style is to subordinate all aspects of the production and presentation of the film to promote a more seamless narrative. Thus, the viewer sits as a silent observer absorbed into the drama and action, unaware of herself, and unaware of how the mechanics of what she is seeing were put together. In this manner, and perhaps somewhat confusingly, many films made throughout the world are in Hollywood style and a few films made in Hollywood are not. Film in Hollywood style is popular film, not typically art film. Along with perhaps popular music, it is the most popular art form worldwide. Because Hollywood style film is so nearly universal, we believe that its structures have deep psychological import for understanding how the human mind works during time spans longer than the instant.

Our sample of 150 films has 10 films from each of 15 years, every five years from 1935 to 2005 . These are listed online in the supplemental material. Using information from a number of sources, we selected films after 1980 that were among those with the highest gross receipts of their release year. Before 1980 those data were not systematically recorded, so we selected among those rated by largest number of viewers on the Internet Movie Database (IMDb, http://us.imdb.com, as assessed on $28 \mathrm{Feb}$, 
2008). The films were also chosen to represent five genres-action (32 films), adventure (20), drama (47), comedy (41), and animated films (10)—where genre is defined typically by the firstdesignated category for each on the IMDb. Most films are assigned to more than one, and our films span 20 different genres. The distribution of films within these genres and within a given year has varied due to changes in Hollywood and in filmgoers' tastes. Pooled ASLs from this sample are also shown in Figure 1 superimposed on Salt's $(1992,2006)$ data. Except for the period overlapping that of the studio era (here 1935-1960), they match Salt's data reasonably well.

In our film preparation we stripped off the audio track and downsampled the frames, altered the aspect ratio (the horizontal extent divided by the vertical extent, ranging from 1.37 to 2.55 ), and stored each as a $256 \times 256$ pixel jpeg file. These adjustments made computations and comparisons across films more tractable. The mean length of these films was about 115 min excluding trailing credits and beginning credits without scenic content.

Our focus is on visual activity within shots. Thus, to assure independence from ASL, we removed the more abrupt changes across cuts from this first analysis. However, we ignored fades, dissolves, wipes, and other transitions since these noninstantaneous changes would not affect our calculations. We had hoped to compare consecutive frames, but quickly discovered that sampling rate changes during commercial digitization of NTSC-formatted media often created hybrid frames. In particular, the last frame of one shot is often overlaid on the first frame of the next, creating a one-frame mixture and a three-frame dissolve. This overlay process occurs within shots as well, and in many films that we analyzed. To avoid this problem, we compared frames separated by one other frame. Thus, we contrasted Frames 1 and 3, 2 and 4, 3 and $5, \ldots 136431$ and 136433, and so forth, serially across each film. This yielded a mean of about 165,000 frame pairs per film.

We chose Pearson product-moment correlation as our method of comparison. Obviously, a correlation $(r)$ of 1.0 would occur when two frames of film are identical. Our central argument is that the lower the correlation value the more visual activity is present, whether measured in a single pair of frames or the amalgam of all near-adjacent pairs across an entire film. We converted the correlations into a visual activity index (VAI) by subtracting the $r$ value from 1.0. This gives VAI a potential range from 0.0 to 2.0. More intuitively, the VAI for two identical frames is now zero; increasingly higher indices correspond to increasingly more visual activity. We should also emphasize that our intent is not to perform spatiotemporal frequency analysis of films (e.g., Dong \& Atick, 1995; Tversky \& Geisler, 2008). The focus of that research is on the rich interrelations between spatial and temporal structure. Instead, our focus is on indexing-providing a single number to represent the visual activity in a film or film sequence.

Correlations were performed on the luminance values (grayscale, 0 to 255) for each of more than 65,000 pixels in each image of a pair. Thus, and when necessary, each image was converted from color to grayscale prior to calculation. Because the nearly adjacent frames of films are typically very similar, it should be no surprise that the average VAI for pairs of frames within the same shot is near zero. Indeed, the median VAI was 0.034 for the nearly 25 million frame comparisons that we made. However, the manner in which these vary within and across films is of more interest.
The distributions for these film measures are far from normal. Consider two shown in Figure 2, those for Anna Karenina (1935) and King Kong (2005). Notice that both are very strongly skewed, with most index values (about 90,000 in each film) equal to 0.05 or less. Each distribution also has a very long rightward tail stretching toward 1.0 and beyond. Indeed, the maximum VAI for a pair of frames in Anna Karenina was 1.46; the maximum in King Kong was 1.75. All 150 films had distributions like these two, and typically between them. They differed only in the length and size of the right-branching tail. Because such distributions are so strongly skewed, we thought that means were not an appropriate index of central tendency. Instead, we will report the median values for each film. The overall VAI (1.0 - median $r$ ) for Anna Karenina is 0.027 and that for King Kong is 0.093 .

To grasp better what these values reflect, consider the images in the first two columns of Figure 3. These are taken from 22 consecutive frames in a single action shot late in the film The Flame and the Arrow (1950) starring Burt Lancaster. The pair in top panel, and the earliest in the shot, has a measured correlation of near zero. Thus, it has a VAI near 1.0. The camera has just completed a short pan to the left with a slight upward tilt, settling on soldier at the right of the frame with two others rushing by him in the foreground. The pair in second panel, a few frames later in the shot, has a VAI near 0.60 . Here, the camera continues a slight upward tilt, while the rear soldier steps forward to issue a command and the second of the foreground soldiers disappears revealing an ornate chair. The index for the third pair is about 0.20 , where the slight upward tilt of the camera continues, the soldier issuing the command leans forward slightly and opens his mouth, and the shadow of the disappearing soldier leaves the chair. Fi-

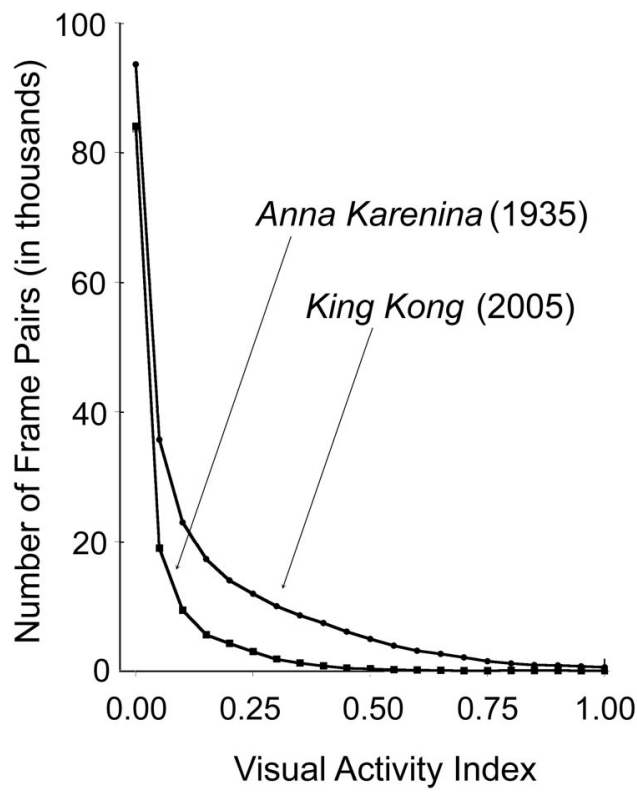

Figure 2. A comparison of the distributions of interframe visual activity indices (VAIs) of two films. Anna Karenina (1935) generated about 132,000 interframe correlations, and King Kong (2005) generated about 255,000. Interframe VAI is 1.0 minus the frame-to-frame correlation $(r)$; sequence or whole-film VAI is $(1.0$ - median $r)$. The whole-film VAI for Anna Karenina is 0.027, and that for King Kong is 0.093 . 


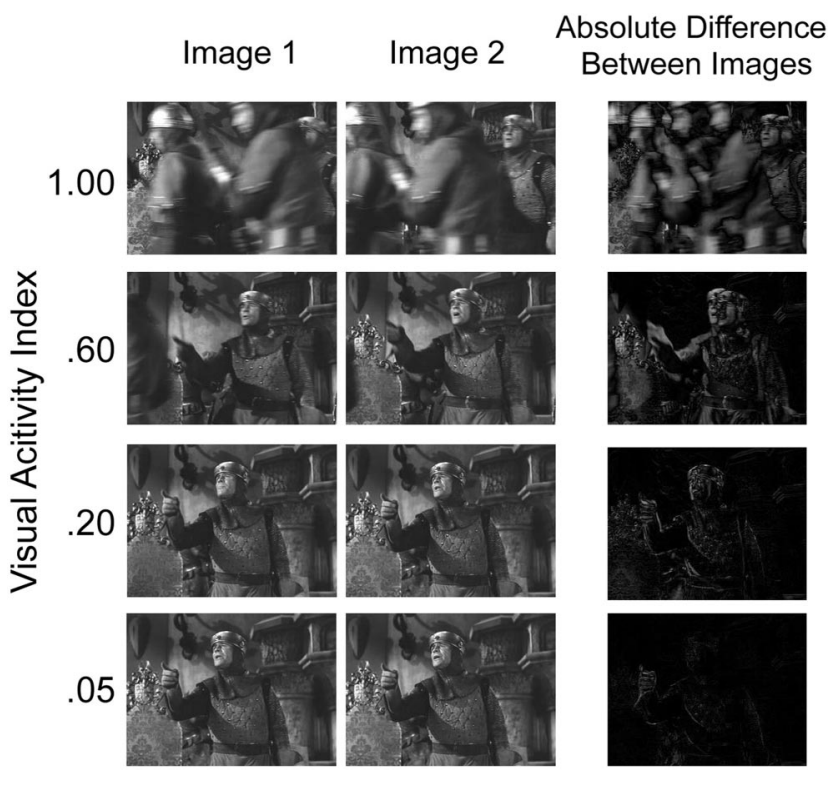

Figure 3. The first two columns show four pairs of black-and-white frames from near the end of color film The Flame and the Arrow (1950). These pairs exemplify visual activity indices (VAIs) of near 1.0, 0.60, 0.20, and 0.05 , which correspond to interframe correlations of near $0.00,0.40$, 0.80 , and 0.95 , respectively. The last column of images shows the absolute value of the difference in pixels for film image pair. Blackness indicates no change in the pixels; increasing lightness indicates increasing differences in pixels across the pair. Images from DVD, copyright 2007 by Warner Home Video.

nally, that for the bottom pair is about 0.05 , where the soldier continues to lean forward and bend his arm.

The last column of Figure 3 shows the absolute value of the difference between the two images in each pair. Here, blackness indicates no difference between corresponding pixels, and thus regions of no motion or movement. Increasing brightness indicates the increase in the difference between corresponding pixels, denoting either motion or movement. Notice that the image pair with a VAI of 0.05 is almost entirely black with only a vague outline of the soldier's arm and body; that the image pair with a VAI of 1.00 is a riot of change; and that the other two images are in between these extremes.

Notice also that all but the last of the values for the image pairs are well above the median VAI for all films (0.034). It is worth remembering that these frames are part of an action sequence, and worth noting that almost all Hollywood films have more than a few pairs of frames with values near 1.00, 0.60, 0.20, and particularly 0.05 shown here. The overall index, however, typically converges on lower values. In most films and most of the time, the camera is stationary, and there is only a modest amount of visual activity.

For other examples of what these values reflect, consider longer sections of three films. Near the end of $M * A * S * H$ (1970) and The Longest Yard (2005), there are football game sequences filmed largely from the playing field. For this 12-min section of $M * A * S * H$ the VAI is 0.190 , and for the 33-min section of The Longest Yard it is 0.240 . These values are probably typical of such sequences in sports films. In addition, The Perfect Storm (2000) has a 45-min set of turbulent sea sequences occasionally inter- rupted with calmer land shots. The VAI for this whole portion of film is 0.199. However, such values do not represent a upper bound for shorter sections in contemporary Hollywood film. Later, we will return to sequences in more extreme action, adventure, and "queasicam" films (Bordwell, 2007; Ebert, 2007) to elucidate more clearly the psychological and cognitive constraints on visual activity.

\section{5 to 2005: Differences Across Time and Genres}

Figure 4 shows the VAIs for 145 films plotted by year. Five early animated films are excluded for reasons that we explain later. Indices for all films are given in the supplemental material. Clearly, from 1935 to 2005 there was an increase in VAIs in popular film $(r=.52, t(143)=6.44, p<.0001)$. The change in the indices for these films is roughly linear from about 0.02 in 1935 to about 0.06 in 2005, as reflected by the regression line. The linearity of this trend is important for it shows a normative change in Hollywood film that reflects no overall discontinuity in the visual activity represented by film style. On the basis of these data, we claim that normative changes in VAI are slow and accrue only over decades.

Figure 5 shows the separate trends for action, adventure, drama, comedy, and animated films. The panels show differences across genres. The same upward trend can be seen for action and adventure films, $r \mathrm{~s}=.53 \& .63, t(30)=3.42 \& t(18)=3.51, p \mathrm{~s}<.005$, as that seen across all films. A slight upward tendency, although not nearly as prominent, can also be discerned among drama, $r=$ $.31, t(45)=2.19, p<.04$, and comedy films, $r=.308, t(39)=$ $2.02, p<.06)$.

The pattern for the animated films is more complicated. Some earlier animated films show more visual activity across frames than do later ones, but yielding no overall significant trend. The earlier movies, indicated with darker dots in Figure 5, are Disney cell animations; Toy Story (1995) was the first completely computer animated film. These cell animated films are hybrids, some-

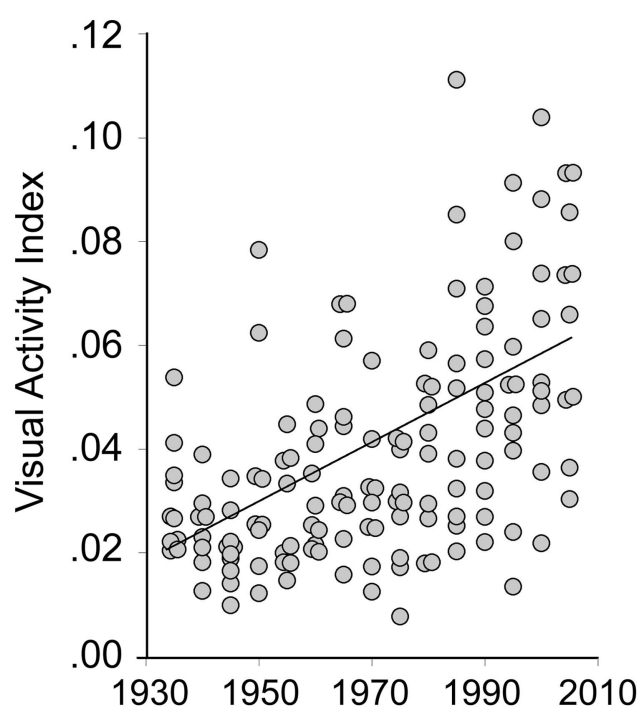

Figure 4. A scatter plot of whole-film visual activity indices (VAIs) by year for 145 films from 1935 to 2005 . 


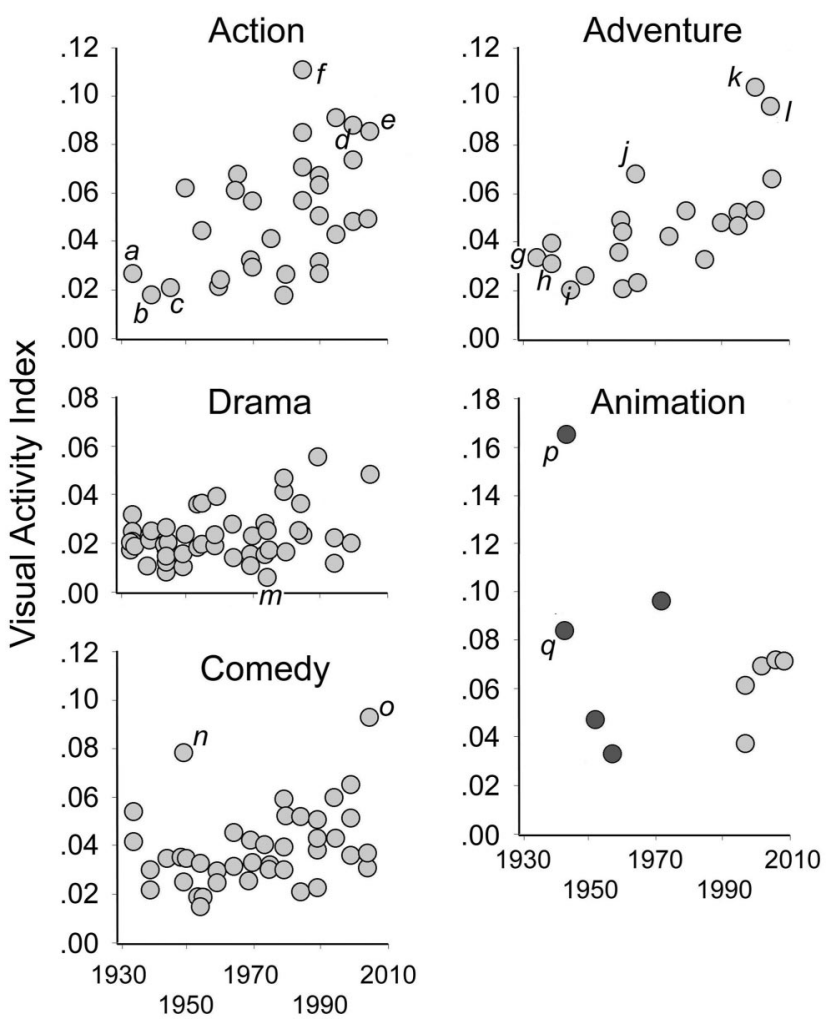

Figure 5. Scatter plots of whole-film visual activity indices (VAIs) by year for five genres of film. Italic letters correspond to the films: (a) Captain Blood, (b) Santa Fe Trail, (c) Blood on the Sun, (d) Charlie's Angels, (e) Mr. and Mrs. Smith, (f) Jewel of the Nile, (g) Mutiny on the Bounty, (h) The Thief of Baghdad, (i) In Pursuit to Algiers, (j) Those Magnificent Men and Their Flying Machines, (k) The Perfect Storm, (1), King Kong, (m) Barry Lyndon, (n) Annie Get Your Gun, (o) The Longest Yard, (p) Pinocchio, and (q) Fantasia. Darker dots correspond to cell animated films.

times composed at 12 frames/s (each frame duplicated) when motion is slow and sometimes at 24 frames/s when it is faster. Salt (2006, pp. 151-161) proposed an animation ratio (the number of duplicated frames divided by the total number of frames) to measure such films; a ratio of .5 would have all frames duplicated and a ratio of 1.0 would have none. The median animation ratios for the cell animated films in our sample is 0.756 ; that for the four computer animations is .928 (less than 1.0 because of holds within shots). Values for individual animated films are given in the supplemental material.

Although it was the best that the economics of cell animation could offer and although it was reasonably adequate on perceptual grounds, cell-animated motion and movement is not nearly as smooth as in computer animated films or as in film in general. The high VAI values for cell-animated films are caused, in part, by the lack of blurring in moving objects and characters across frames. Technically, this is known as motion aliasing (see, e.g., Cutting, 2005). Notice, that with computer animation the later films have VAIs in the same ballpark as action and adventure films, about 0.07. It would seem clear that children have no difficulty in following such visually active films as Madagascar (2005, VAI =
0.074) and Chicken Little (2005, 0.073), which are essentially the same as Mission: Impossible II (2000, 0.074).

Again, to understand better what these correlations correspond to, consider particular films in the categories. The early action films include (a) Captain Blood (1935, 0.027), a Caribbean swashbuckler with Errol Flynn, Basil Rathbone, and Olivia de Havilland; (b) Santa Fe Trail (1940, 0.018), a pre-Civil War epic with Flynn, de Havilland, Raymond Massey, and Ronald Reagan (as George Armstrong Custer); and (c) Blood on the Sun (1945, 0.021), a World War II thriller with James Cagney. All of these have a number of action sequences, but none are as sustained as in films today. Moreover, they are interspersed with long sections of visually quiet plot development. Thus, their overall VAIs are in the same range for films in the other genres of their time. In contrast, however, consider: (d) Charlie's Angels (2000, 0.088), the girlgroup crime-fighter flick with Cameron Diaz, Drew Barrymore, and Lucy Liu; and (e) Mr. and Mrs. Smith (2005, 0.086), the Brad Pitt and Angelina Jolie vehicle for high-velocity domestic violence. In each of these later films, there is dense and sustained visual activity, in contrast to both earlier films and other films of their same release year. The film with the highest VAI among this group was (f) The Jewel of the Nile (1985, 0.111), the Michael Douglas and Kathleen Turner sequel to Romancing the Stone of the previous year.

Similar patterns can be seen among adventure films, although typically not as extreme. Consider: (g) Mutiny on the Bounty (1935, 0.035), the original of these South Sea tussles between Captain Bligh (Charles Laughton) and Fletcher Christian (Clark Gable); (h) The Thief of Baghdad (1940, 0.027), the first sound version of stories taken from One Thousand and One Nights showing Hollywood's early view of the Islamic golden age; and (i) In Pursuit to Algiers (1945, 0.020), with Basil Rathbone as Sherlock Holmes. Each of these films has moments of quick action, but their VAIs are again not different from their other-genre contemporaries. More recent adventure films, however, have much more activity. One is (j) Those Magnificent Men and Their Flying Machines (1965, 0.068), the Terry-Thomas romp through early aviation and high society. Much of the visual activity is due to soaring, low-altitude biplanes. Two more recent films are $(\mathrm{k})$ The Perfect Storm (2000, 0.104), already discussed, the George Clooney vehicle about fishing and tumultuous weather off Gloucester, Massachusetts, and (1) King Kong (2005, 0.093), the Peter Jackson remake of the classic 1933 thriller about a giant ape and New York.

Perhaps not surprisingly, dramas often have the least amount of visual activity, with indices in the range of 0.01 to 0.04 . Indeed, the least active film in our sample is (m) Barry Lyndon (1975, 0.008), the story of an 18th century rogue's loves and sometimes forced travels. Director Stanley Kubrick seems to have been more fascinated with his newfound ability to film by candlelight than with his need to advance the plot. Comedies often have somewhat more visual activity than dramas, with indices typically between 0.02 and 0.06. One outlier in the comedy panel is (n) Annie Get Your Gun (1950, 0.078), the biopic musical about Annie Oakley that has a number of action scenes on horseback. Another is (o) The Longest Yard (2005, 0.093), mentioned above, the Adam Sandler remake of the 1984 Burt Reynolds film about a has-been football player sent to prison. Among animations, the clear outlier is the early cell-animated film (p) Pinocchio (1940, 0.166). We also note 
that (q) Fantasia (1940) has an index of 0.090 when only the animated sequences are considered, but an overall VAI of 0.065 .

Intriguingly, several differences among these genres are statistically reliable. Over the 70 years of our sample, action films have diverged from drama, $R^{2}=.36, F(1,75)=42.87, p<.0001$, using a regression contrast; and from comedy films, $R^{2}=.12, F(1$, $71)=9.51, p<.003$, with increasingly more visual activity compared to the other two. Action and adventure films, however, are not reliably different. Clearly, both genres trade on visual activity as a source of viewer involvement. Also, both adventure and comedy films have diverged from dramas, $R^{2} \mathrm{~s}=.22 \& .16$, $F \mathrm{~s}(1,87 \& 65)>16.3, p \mathrm{~s}<.001$, although not statistically from one another. This fanning out of visual activity values across genres created the increase in variance among more recent-year releases that is apparent in Figure 4. In other words, genre is a more important predictor of visual activity today than in years past. The fanning pattern also demonstrates that action and adventure films today are increasingly less representative of movies as a whole, whether measured in terms of visual activity or, likely, in ASL.

On the basis of the results reported here, we suggest that contemporary viewers have grown accustomed to, and desire to see, films with more visual activity than those that their parents and grandparents enjoyed. This may serve as a partial rationale for, if not to justify, the endless remakes that Bordwell (2002, p. 16) bemoaned. Remakes will almost surely have more visual activity than the originals. We have no such pairs in our sample, but this trend is true even for a spoof of an earlier drama (Airplane!, 1980, 0.039 vs. Airport, 1970, 0.025). This pattern is likely true in most series films as well, with later films having more visual activity. For example, among the Star Wars films The Revenge of the Sith (2005, 0.050) has a higher index than The Empire Strikes Back (1980, 0.027). Although it can be statistically ill advised to extrapolate beyond the data one has in hand, we expect more and more activity in films of the near future, with action and adventure films leading the way.

\section{Visual Activity Indices (VAIs) and Average Shot Lengths (ASLs)}

Since 1935 mean shot lengths have been generally decreasing and visual activity has been increasing. What is the relationship between the two? Previously, when we parsed these films into their shots (Cutting et al., 2010), we also determined their ASLs. The correlation between ASL and VAI is reliable, $r=-.46$, and $r=$ -.55 when ASL is log scaled, $t \mathrm{~s}(148)>6.03, p \mathrm{~s}<.001)$, but remember there can be no causal relation here. The scatter plot is shown in the top panel of Figure 6 and ASL and VAI values for each film are given in the supplementary material. Among the 150 sample films, each represent by a black dot, it is not difficult to find movies with relatively long ASLs but relatively high VAIs. Two examples are (a) Top Hat (1935, ASL = $10.5 \mathrm{~s}$, VAI = 0.041), in part because Fred Astaire insisted that dance numbers not be interrupted with cuts; and (b) Cast Away (2000, 9.22 s, 0.053 ) with many long duration shots of watery scenes. And there are a number of films with relatively short ASLs but generally low VAIs. Two are (c) Superman II (1980, 3.89 s, 0.018) and (d) Hitch (2005, $3.83 \mathrm{~s}, 0.036)$. Among our sample films, the outlier in Figure 6 is again (e) Annie Get Your Gun (1950, 14.9 s, 0.078); and

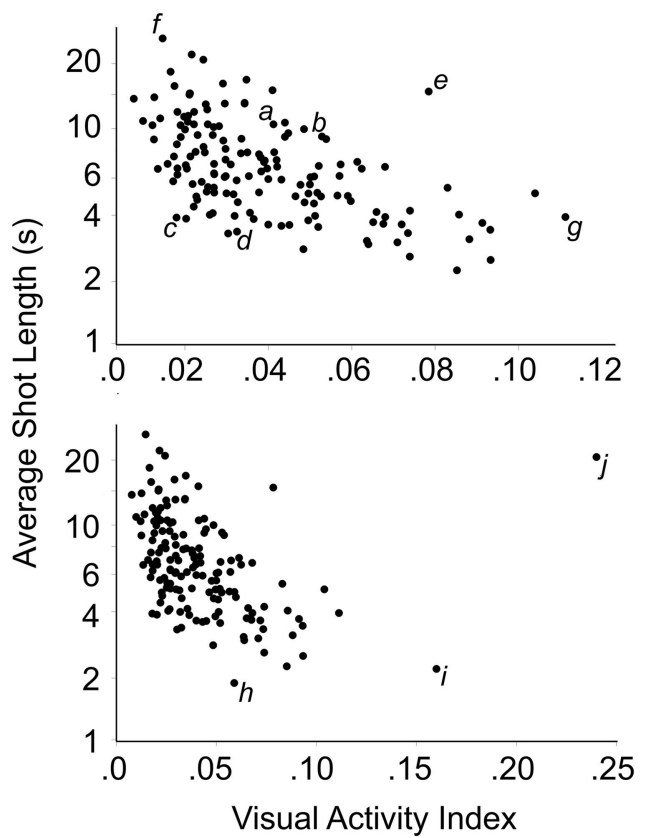

Figure 6. Two scatter plots of the whole-film visual activity indices (VAIs) against average shot lengths (ASLs, log scaled). The top panel represents the 150 films in our sample, the lower panel has a rescaled abscissa to include three newer films. Italic letters correspond to the films: (a) Top Hat, (b) Cast Away, (c) Superman II, (d) Hitch, (e) Annie Get Your Gun, (f) The Seven Year Itch, (g) The Jewel of the Nile, (h) Quantum of Solace, (i) The Bourne Ultimatum, and (j) Cloverfield.

the extremes of the main negative trend are (f) The Seven Year Itch (1955, $26.2 \mathrm{~s}, 0.015)$, and again (g) The Jewel of the Nile (1985, $3.92 \mathrm{~s}, 0.111)$.

\section{High Visual Activity Films and Film Sequences}

Our general interests are in the relationship between the physical attributes of Hollywood film and human perceptual and cognitive systems. Having established the increase in visual activity, and the decrease in shot lengths in films over the last 70 years, a new question arises: is there a limit to the amount of this activity (or to the brevity of ASLs) that a Hollywood film can sustain? We think so, but it surely depends in part on the duration of the particular sequence. However useful whole-film ASLs and VAIs may be, there is always considerable variation within any film. Thus, in discussing possible processing limits it seems more appropriate for us to focus on sequences and groups of sequences with the highest VAIs (and shortest ASLs) not on whole films.

We will approach this topic two ways, but first let us revise our notion of visual activity. It was useful earlier to discard the changes that occur across cuts from calculations of visual activity to assure the independence of our index from ASL. However, the VAI computations are hardly changed when across-cut correlations are included-adding roughly 1,000 numbers to about 165,000 others and then reassessing the overall median will barely alter the outcome. Thus, the VAIs reported below include frameto-frame correlations throughout all films and film sequences, across cuts and all. Now, to divide our earlier question in two: 
First, are there known limits to the brevity of ASLs or the magnitude of VAIs? No, but consider a thought experiment. Imagine a hypothetical film composed of random photographs. If shown at $12 \mathrm{images} / \mathrm{s}$, it would have an extremely short ASL (0.08 s) and high VAI (1.00, assuming the images are uncorrelated, $r \mathrm{~s}=.0)$. It seems unlikely that anyone could watch a film with shots flickering like this and extract much content from it, much less pay money to see it. Of course, there are laboratory findings near this extreme. We know from perceptual experiments that viewers can make some sense of static images shown in rapid serial visual presentations (RSVPs) of still pictures. The maximum rate for some comprehension-the ability of viewers to identify what they have been told what to look for-is about $100 \mathrm{~ms}$ per picture (ASL $=0.10$ s, e.g., Potter, 1976; Potter \& Fox, 2009), although the whole stimulus sequence is rarely as long as $2 \mathrm{~s}$. By our calculations this presentation would produce a VAI of about 0.82 , well more than that for any whole film or sequence in our sample. Indeed, it seems likely that such an index is well beyond any bound that a Hollywood film could sustain for more than a brief period of time.

Second, can we obtain data from existing films to discern possible limits to VAIs? Yes, we believe so. Consider some sequences from films in our sample, and a few from beyond it. Twenty-two sequences of film from 14 different movies are listed in Table 1, with their lengths, VAIs, and ASLs. Also listed is the point from the beginning of the film that the sequence begins. Three longer sequences have already been discussed-those from $M * A * S * H$, The Longest Yard, and the entire high turbulence portion of The Perfect Storm. In addition, Figure 3 shows selected frames from The Flame and the Arrow action sequence listed in Table 1. The constraints on this collection are that the sequence must be about three minutes long or more, and it must have a VAI of 0.150 or higher. Fifteen from this list exhaust all such sequences among the 150 films in our sample.
We also made an effort to be more current, and to push our analyses of visual activity more to the extreme. Thus, we went outside our sample and analyzed three more recent movies chosen for their visual intensity: (h) Quantum of Solace (2008), (i) The Bourne Ultimatum (2007), and (j) Cloverfield (2008). The ASLs and VAIs of these three appear in the bottom panel of Figure 6. They clearly fall outside the pattern created by the 150 films of our sample.

Consider first the James Bond film, Quantum of Solace, 22nd in the series of these action films about the mythical British secret agent. We concentrated on its four action sequences that met our criteria. At the beginning of the film, there is a nearly 3-min coastal tunnel to quarry car chase. Its extremely rapid cutting rate $(\mathrm{ASL}=0.82 \mathrm{~s})$ aside, this sequence has a VAI of 0.290. Again, this value is much above that for any whole film. The second chase sequence is longer and has even more activity. It lasts almost 4.5 min and takes place in and around the Palio di Siena (the horse race in the city center) with parkour rooftop leaps (ASL $=0.84 \mathrm{~s}$, VAI $=0.356$ ). A third, a chase of planes and helicopters, is about the same $(1.07 \mathrm{~s}, 0.354)$ and the final action and escape sequence, where a desert hotel is burned, emphasizes fast cuts over activity (1.01 s, 0.219). However, despite these minutes-long eruptions of visual action and an overall high cut rate $(\mathrm{ASL}=1.85 \mathrm{~s})$ Quantum of Solace has a whole-film VAI of only 0.059. Surprisingly, this is less than that for Thunderball $(1965,0.068)$, the 4th James Bond film from more than 40 years earlier. The relatively high activity in the latter is partly due to its many underwater scenes.

This pair of Bond films shows several things. One is that more recent films in a series do not always have more visual activity. Another is that, as seen in Table 1, sequences with high visual activity have been around for a long time. There is a 3-min escape sequence through the Bahamian Junkanoo (Nassau's Boxing Day street festival) in Thunderball that has a median VAI of 0.307 $(\mathrm{ASL}=2.1 \mathrm{~s})$. Much of this sequence is peppered with jiggling

Table 1

A Comparison of Most Visually Active Selected Sequences in Action, Adventure, and Comedy Films

\begin{tabular}{|c|c|c|c|c|c|}
\hline & Sequence description & $\begin{array}{l}\text { Minutes into } \\
\text { the film }\end{array}$ & $\begin{array}{l}\text { Length of } \\
\text { sequence }\end{array}$ & $\begin{array}{l}\text { Visual activity } \\
\text { index (VAI) }\end{array}$ & $\begin{array}{c}\text { Average shot } \\
\text { length (s) }\end{array}$ \\
\hline Cloverfield (2008) & Brooklyn Bridge evacuation & 24.4 & 4.3 & 0.576 & 19.7 \\
\hline \multirow[t]{4}{*}{ Quantum of Solace (2008) } & Tunnel and quarry auto chase & 0.6 & 2.9 & 0.290 & 0.8 \\
\hline & Palio and rooftop chase & 10.5 & 4.4 & 0.356 & 0.8 \\
\hline & Plane and helicopter chase & 66.7 & 4.3 & 0.354 & 1.1 \\
\hline & Hotel fire, fight, and escape & 90.8 & 4.0 & 0.219 & 1.0 \\
\hline \multirow[t]{2}{*}{ The Bourne Ultimatum (2007) } & Tangier chase & 57.7 & 6.3 & 0.384 & 1.6 \\
\hline & New York City chase & 83.9 & 7.0 & 0.377 & 1.3 \\
\hline Harry Potter/Goblet (2005) & Test 1: flying dragon & 58.2 & 3.8 & 0.196 & 2.1 \\
\hline \multirow[t]{2}{*}{ King Kong (2005) } & Dinosaur stampede & 75.7 & 3.4 & 0.435 & 3.0 \\
\hline & Kong vs. 3 T. rexes & 104.1 & 4.6 & 0.390 & 1.9 \\
\hline The Longest Yard (2005) & Football game & 69.6 & 32.6 & 0.240 & 2.7 \\
\hline Mission: Impossible II (2000) & Motorcycle chase & 101.7 & 7.8 & 0.257 & 1.4 \\
\hline Cast Away (2000) & Downed plane & 23.3 & 5.9 & 0.249 & 4.1 \\
\hline \multirow[t]{2}{*}{ Perfect Storm (2000) } & Failed helicopter rescue & 91.9 & 3.0 & 0.297 & 3.3 \\
\hline & Entire storm sequence & 70.9 & 45.0 & 0.199 & 3.6 \\
\hline Batman Forever (1995) & Destruction of the Riddler's lair & 100.7 & 13.9 & 0.173 & 2.3 \\
\hline \multirow[t]{2}{*}{ Jewel of the Nile (1985) } & Wingless jet plane escape & 42.7 & 7.6 & 0.160 & 2.2 \\
\hline & Climax fire and escape & 94.2 & 4.8 & 0.199 & 2.5 \\
\hline$M^{*} A^{*} S^{*} H(1970)$ & Football game & 97.6 & 11.8 & 0.190 & 3.3 \\
\hline \multirow[t]{2}{*}{ Thunderball (1965) } & Junkanoo festival escape & 85.9 & 3.1 & 0.307 & 2.5 \\
\hline & Underwater fight in wetsuits & 111.9 & 11.3 & 0.150 & 2.5 \\
\hline The Flame and the Arrow (1950) & Castle circus and escape & 74.0 & 9.2 & 0.169 & 4.5 \\
\hline
\end{tabular}


lights and sequins on dancers. Nonetheless, in both films the chases and escapes are interleaved with visually quiet periods. This suggests that, to accommodate viewers, locally intense sequences need to be interleaved with less active periods. Such patterns are consistent with our account of shot-length fluctuations in films (Cutting et al., 2010), and we will return to this idea later.

The second movie outside our sample is The Bourne Ultimatum (2007), the third installment and film adaptation of Robert Ludlum's novels about an amnesic CIA agent. Ebert (2007; see also Bordwell, 2007) dubbed this a "queasicam" film. That is, it was filmed deliberately eschewing the utility of steadicams (steady cameras), which were invented to allow mobile cameras to have more nearly steady focus. More than simply having large amounts of motion, these films are filled with large amounts of unsteady camera movement. They have just enough-or perhaps not nearly enough, depending on one's stomach-correlation across frames in the large features of a scene for the viewer to get the gist of the action. Queasicam films violate gaze-stability, an extremely important vision-movement system with sophisticated neural control that has evolved over millions of years (e.g., Berthoz, 2000; Goodkin, 1980). In particular, the gaze-stability system allows us to see better while we move, reflexively negating the small eye rotations that occur while we are bouncing up and down as we walk or run. Queasicam sequences take a good part of that visual control away. Steadicams, on the other hand, mimic gaze-stability processes and their products have been much appreciated by filmmakers and filmgoers alike. It is no surprise that queasicam action heightens emotional response in viewers. It also leads to poorer visual acuity in the viewer and, as noted by Bordwell (2007), makes fewer demands on acting, content, and camera work.

Some of the action sequences in Ultimatum are very high in visual activity. For example, the 7-min New York City chase sequence near the end of the film has a VAI of 0.377 , and the index for the entire film is also very high (0.160), indeed quite a bit higher than any film in our sample. Not every viewer seems to have appreciated this activity, and some felt that it was excessive (Ebert, 2007). But Ultimatum was soon eclipsed.

The third film is Cloverfield (2008), regarded by many as having pushed beyond the limit of acceptable visual activity (Ebert, 2008). Cloverfield is a mystery/sci-fi movie of an alien attack on New York City. It is filmed as if it were a documentary (and hence called a mockumentary) with very long shots (ASL $=20.6 \mathrm{~s}$ ) from a shoulder-mounted camera that roams through buildings, streets, subways, and ends in Central Park. Movement and motion are combined throughout the film. Compared to the films in our sample, its median VAI is a remarkable 0.240 sustained over 73 min. The most active sequence in Cloverfield is the 4.3-min failed pedestrian evacuation over the Brooklyn Bridge (VAI $=0.575)$. Its level of visual activity is far above anything found in any sequence in the other 152 films.

Our belief is that, in terms of visual activity, Cloverfield cuts it pretty close to what most people will tolerate, and is beyond the tolerance of many viewers. This is particularly true when projected on a large screen and engaging large amounts of the visual periphery, which is responsible for balance and a sense of stability (Duh, Lin, Kenyon, Parker, \& Furness, 2002; Leibowitz \& Post, 1982). Indeed, movie theaters often felt it necessary to post warnings outside ticket booths when showing the film. It is clear from online chatter that a sizable portion of its audience was not appreciative; more than a few were nauseated and became physically ill. Indeed, although it was the 5th most rated film on the IMDb for 2008 (assessed both 20 Jan and 25 June 2010), it was only tied for 53rd best liked film of that year (20 Jan 10) and later trailed off to 61 st (25 June 10). We suspect that films do better when using a queasicam more selectively. Indeed, it is well used throughout much of the almost 6-min downed plane sequence in Cast Away $(2000$, VAI $=0.249)$.

In summary, we suggest that these three films are representative of two different dimensions related to what Bordwell (2002, 2006) has called intensified continuity in contemporary Hollywood film. As seen in the lower panel of Figure 6, Quantum of Solace has a very brief ASL, but relatively modest VAI. Cloverfield is the opposite; it has a very long ASL but an astonishingly high VAI. And The Bourne Ultimatum combines both with a short ASL and a high VAI.

\section{A Framework for Predicting the Effects of Visual Activity in Film as a Function of Duration}

For more than a century films have told stories, some of the highest art and others of the worst drivel. Throughout this period, films have also forged and maintained a firm place within popular culture. Given that place and even allowing for cultural change, films must still conform to the general constraints of our perceptual and cognitive systems, all the while exploring techniques that make them appear new and different. Some techniques are used to increase viewer emotions and involvement. A rapid cutting rate is clearly one of these, but since we haven't systematically studied it here, we have little to offer other than that the rates seen in sequences of Quantum of Solace (2008, ALSs $\sim 0.8$ s) may be pushing a limit sustainable in film. These action sequences are not (yet) close to RSVP rates, but they are also much longer than typical RSVP stimuli. Queasicam films, with their incessant camera motion, employ another relatively new and nonstandard technique, although Bordwell (2007) noted many antecedents. This technique dramatically boosts visual activity, the focus in this article.

Our basic notion about visual activity and duration is this: viewers need relief after being visually and cognitively challenged. A few moments of visual chaos is fine, often even desirable, but some refractory period must follow. Can we predict how much visual activity is too much and for how long? Figure 7 presents our suggestion, along with five types of data. Plotted there are the VAIs for a wide variety of films, film sequences, and film fragments as a function of the logarithm of their duration.

Starting at the lower right there is, first, a mass of black dots that represent the 150 films in our sample, most of which had no goal of presenting a high intensity visual experience. Second and moving leftward, the dots with gray centers represent all film sequences from Table 1. Third, to the left of those are the most active fragments in the film sequences of Table 1 . To determine these, we ran a traveling window of $60,10,3$, and $1 \mathrm{~s}(1440,240,72$, and 24 frames) down the length of those sequences, regardless of content or cuts, and chose the value of that fragment with the highest VAI. Those open circles staggered slightly to the right are from the three newer films outside our sample; those staggered slightly left are from the sequences in our sample films. Fourth, embedded among 


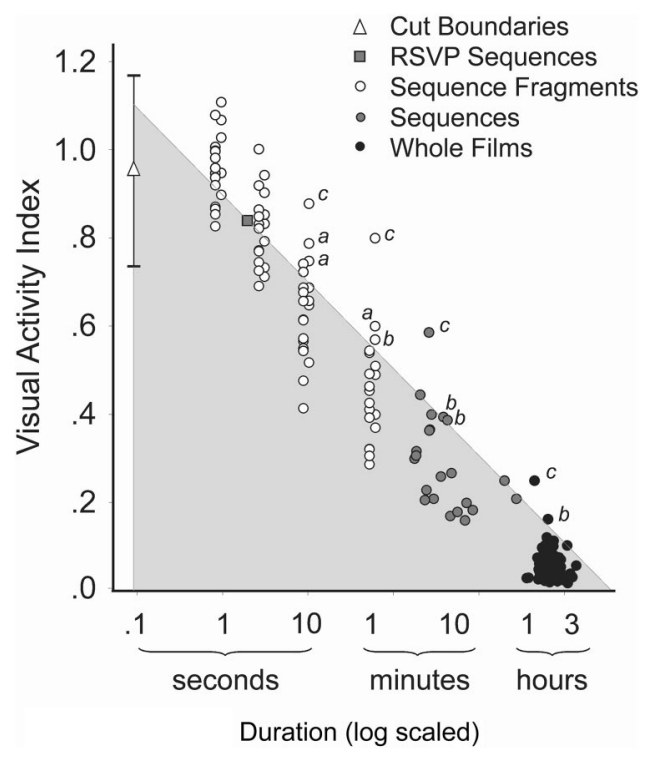

Figure 7. A scatter plot of visual activity indices (VAIs) against log duration for whole films, film sequences from Table 1, fragments of sequences from the three more recent films (staggered right) and those from the sample sequences in Table 1 (staggered left), rapid serial visual presentation (RVSP) data, and differences across cuts. A rough threshold is proposed, running through RVSP data and above the bulk of films, concerning a generally tolerable amount of visual activity as a function of duration. Films, sequences, and fragments associated with italic letters are from (a) Quantum of Solace, (b) The Bourne Ultimatum, and (c) Cloverfield.

these is as a gray filled square serving as a benchmark for RSVP presentations of static images at $100 \mathrm{~ms} / \mathrm{image}$ for $2 \mathrm{~s}$. And finally at the far the left is an open triangle representing the grand median activity index measured across the roughly 160,000 cuts from our sample films, bracketed by plus and minus the median standard deviation per film.

The diagonal border in this figure is not a regression line. Instead, it is our suggestion of where filmmakers need to begin to be careful in crafting their film sequences. We propose it as a soft, psychological limit. When above this line, film sequences surely heighten viewers' responses, which is generally good in many contexts. But in domains of a few seconds they also flirt with viewer incomprehension, and in domains of minutes and longer they may create discomfort. To be clear, the idea is a graded one; some viewers may thoroughly enjoy the heightened action as it approaches visual chaos, but this accrues at the cost of dampening the enjoyment by others.

Our border is drawn so that it is anchored near one end by the well-studied data point for RSVP sequences, a reference where knowledgeable viewers can just barely discern the content of flashed images. It is anchored at the other end to include beneath it all 150 films in our sample. Bounded by or falling below this line in the gray area are all films in our sample and all of their sequences and sequence fragments longer than $10 \mathrm{~s}$. Only the whole film King Kong (2005) and its dinosaur stampede sequence are on the line.

Two whole films represented as black dots in Figure 7 appear above this line, both outside our sample: (b) The Bourne Ultima- tum, and (c) Cloverfield. Most of the 22 sequences of Table 1, represented by gray-filled dots, also fall beneath the line but there are a few that do not. The two chase sequences from The Bourne Ultimatum, again both labeled $b$, straddle the line. Well above the line is sequence point $c$ represents Cloverfield's failed pedestrian evacuation sequence over the Brooklyn Bridge. To the left of the sequences are the most active fragments from sequences listed in Table 1. The minute-long fragment labeled $a$ is from the Palio sequence in Quantum; that labeled $b$ is from the New York chase in Ultimatum; and $c$ is again from the bridge sequence in Cloverfield. To the left of these are the 10-s fragments. Noteworthy are two from Quantum (again the Palio, and also from the final burning hotel sequence) and one from Cloverfield's bridge sequence. And finally, among the 3-s and 1-s fragments there are a number that fall above the line, both from the three high-intensity films and from the 11 films from our sample listed in Table 1. Our view is that this is generally fine; viewers probably don't mind being nearly clueless about what is going on for such brief periods.

Whereas Figure 7 represents patterns across many different sources-whole films, film sequences, film fragments, cuts, and RVSP stimuli-it is worthwhile considering the VAI fluctuations in a single, high intensity film. These are shown in Figure 8 for The Bourne Ultimatum. We first parsed this 105-min film into 632 consecutive 10-s intervals (e.g., including frames 1-240, 241-480, 481-720, etc.), regardless of cuts or content. We then measured the VAI for each of those intervals, and binned them into activity regions of 0.0 to $0.1,0.1$ to $0.2,0.2$ to $0.3,0.3$ to $0.4,0.4$ to 0.5 , 0.5 to 0.6 , and 0.6 to 0.7 VAI. The maximum VAI value for all 10 -s intervals of this film was 0.624 . The relative proportion of

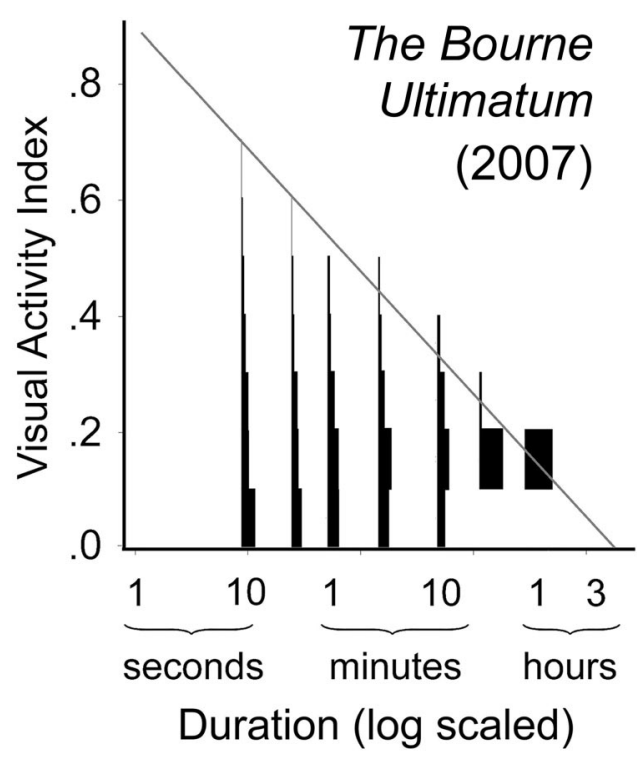

Figure 8. A representation of the fluctuation of visual activity in The Bourne Ultimatum in windows of 10 and $30 \mathrm{~s} ; 1,3,10$, and $30 \mathrm{~min}$; and $1 \mathrm{hr}$. The widths of the horizontal bars, vertically stacked, represent the proportion of time throughout the whole film that the visual activity index (VAI) remains within a particular VAI interval noted on the ordinate. The width of the bar at $1 \mathrm{hr}$ represents $100 \%$; that is, at all possible 1-hr intervals throughout the 105-min film the VAI remains between .10 and .20 . 
time (represented as width) that the VAI of the movies stays within each of these 10-s bins is plotted in the leftmost stack of horizontal bars. Even in this high intensity film fully $37 \%$ of the film stays at activity levels between 0.0 and 0.1 , and only $0.3 \%$ of the film erupts to a VAI above 0.6.

We next binned overlapping 30-s segments of the film, honoring the 10-s increments above (, e.g., including frames 1-720, 241$960,481-1200$, etc.), and placed them into the same activity regions as before. The second stack of horizontal bars representing these 30-s intervals shows a similar pattern: in 35\% of these time slices The Bourne Ultimatum stays at a VAI below 0.1. It never attains a 30 -s burst of activity as high as 0.6 (the maximum is 0.575 ), but it does manage to maintain VAIs between 0.5 and 0.6 for $2 \%$ of the film. Similarly, across the figure are represented the patterns of visual activity for segments of 1, 3, 10, and 30, and 60 min. Notice that by 3-min intervals the film spends more time between VAIs of 0.1 and $0.2(37 \%)$ than between 0.0 and 0.1 $(30 \%)$, and this shift maintains itself throughout the larger intervals. The single bar at one hour represents the finding that in all possible 1-hr intervals across the film, the VAI maintains itself between 0.1 and 0.2 .

The pattern of analyses shown in Figure 8 demonstrates that visual activity fluctuates greatly across films and that high VAI values near the diagonal are relatively rare at shorter intervals. The Bourne Ultimatum generally has a large number of moderately active intervals that accumulate and give the film a much higher than normal VAI index for the whole film, as shown in the lower panel of Figure 6. Perhaps the most important aspect of Figure 8, however, is that even in this visually intense film there is only a relatively small amount of film footage that exceeds our suggested soft boundary of visual activity, except at the largest interval measure (1 hr).

Stepping back, however, one might worry that the diagonal lines drawn in Figures 7 and 8 is subject to cultural revision. More concretely, it might be that VAI changes in the future could occur in the same way that they have for ASLs shown in Figure 1. This is possible but, at least for us, it seems unlikely. In Figure 7 all but one of the fragments, sequences, and films above this line lasting longer than $10 \mathrm{~s}$ are from queasicam films. We believe that gaze-stability is too important and ingrained in our biological makeup to be very malleable to cultural influence. Thus, we suspect that queasicam films will not come to dominate Hollywood film and will remain relatively rare. This does not mean, however, that queasicam sequences will not continue to be used effectively.

In sum, our purpose in these VAI-log duration plots is to suggest a possible linear boundary, running from RVSP experiments through the most intense action sequences of Hollywood films to the films in their entirety. We propose that past and future film sequences, particularly in popular action and adventure films, have dodged and will continue to dodge around this boundary, flirting with it to elevate viewer response before returning to the visually and cognitively less demanding region below the line. We also suggest that the pacing of high visual activity with visual relief is important, reinforcing the importance of rhythms in film that we have investigated elsewhere (Cutting et al., 2010).

\section{Summary}

We have provided a new metric for the measurement of motion and movement in films, which we have dubbed the visual activity index (VAI). Its value if determined by $(1-$ median $r)$ and is based on frame-to-frame correlations of pixels along the length of a film or film sequence. We found that, in a sample of 150 Hollywood films, there has been a linear increase in this metric from 1935 to 2005 generally, and across five different genres, particularly in action and adventure films. We found VAIs to be correlated with average shot lengths (ASLs), but they are also easily differentiated in particular films. Indeed, we suggest that, in any future measure of intensified continuity of films (Bordwell, 2006) that at least the two dimensions of ASL and VAI be considered.

In addition, we explored a possible limit to acceptable visual activity in Hollywood film using RSVP data and the VAIs from the most active film sequences and fragments in our sample and in three visually intense contemporary films. We suggest a linear tradeoff between the measured index value and the logarithm of sequence duration. More generally, the longer the sequence the less likely that high visual activity would prove acceptable to the filmgoer, and the shorter the sequence the more visual activity would be tolerated. Most sequences and sequence fragments that exceeded this limit were found in "queasicam" films, those filmed with a deliberately unsteady camera. We claim that such camera movement violates viewers' expectations of gaze-stability, an ancient adjunct to the eye-movement system that evolved to steady our visual images while we move.

\section{References}

Berthoz, A. (2000). The brain's sense of movement. Cambridge, MA: Harvard University Press.

Bordwell, D. (2002). Intensified continuity. Film Quarterly, 55, 16-28.

Bordwell, D. (2006). The way Hollywood tells it. Berkeley, CA: University of California Press.

Bordwell, D. (2007, August 17). Unsteadicam chronicles. Retrieved from http://www.davidbordwell.net/blog/?p=1175

Bordwell, D., Staiger, J., \& Thompson, K. (1985). The classical Hollywood cinema: Film style \& mode of production to 1960. New York: Columbia University Press.

Cutting, J. E. (2005). Perceiving scenes in film and in the world. In J. D. Anderson \& B. F. Anderson (Eds.), Moving image theory (pp. 7-27). Carbondale, IL: Southern Illinois University Press.

Cutting, J. E., DeLong, J. E., \& Nothelfer, C. E. (2010). Attention and the evolution of Hollywood film. Psychological Science, 21, 440-447.

Dmytryk, E. (1984). On film editing. Boston: Focal Press.

Dong, D. W., \& Atick, J. J. (1995). Statistics of natural time-varying images. Network: Computation in Neural Systems, 6, 345-358.

Duh, H. B.-L., Lin, J. J. W., Kenyon, R. V., Parker, D. E., \& Furness, T. A. (2002). Effects of characteristics of image quality in an immersive environment. Presence, 11, 324-332.

Ebert, R. (2007, August 16). Shake, rattle, and Bourne. Retrieved from http://rogerebert.suntimes.com/apps/pbcs.dll/article?AID=/20070816/ COMMENTARY/70816001

Ebert, R. (2008, January 17). Cloverfield. Retrieved from http:// rogerebert.suntimes.com/apps/pbcs.dll/article?AID =/20080117/ REVIEWS/801170302

Gibson, J. J. (1954). The visual perception of objective motion and subjective movement. Psychological Review, 61, 304-314.

Gilden, D. L. (2001). Cognitive emissions of 1/f noise. Psychological Review, 108, 33-56. 
Gilden, D. L., Thornton, T., \& Mallon, M. W. (1995, March 24). 1/f noise in human cognition. Science, 267, 1837-1839.

Goodkin, F. (1980). The development of mature patterns of head-eye coordination in the human infant. Early Human Development, 4, 373386.

Hasson, U., Landesman, O., Knappmeyer, B., Vallines, I., Rubin, N., \& Heeger, D. J. (2008). Neurocinematics: The neuroscience of film. Projections, 2, 1-26.

Hasson, U., Nir, Y., Levy, I., Fuhrman, G., \& Malach, R. (2004, March 12). Intersubject synchronization of cortical activity during natural vision. Science, 303(5664), 1634-1640.

Leibowitz, H. W., \& Post, R. B. (1982). The two modes of processing concept and some implications. In J. Beck (Ed.), Organization and representation in perception (pp. 343-363). Hillsdale, NJ: Erlbaum.

Messaris, P. (1994). Visual literacy: Image, mind, and reality. Boulder, CO: Westview Press.

Ondaatje, M. (2004). The conversations: Walter Murch and the art of editing film. New York: Random House.

Potter, M. C. (1976). Short-term conceptual memory for pictures. Journal of Experimental Psychology: Human Learning and Memory, 2, 509522.

Potter, M. C., \& Fox, L. F. (2009). Detecting and remembering simultaneous pictures in rapid serial visual presentation. Journal of Experimental Psychology: Human Perception and Performance, 35, 28-38.

Pressing, J., \& Jolley-Rogers, G. (1997). Spectral properties of human cognition and skill. Biological Cybernetics, 76, 339-347.

Salt, B. (1992). Film style and technology: History and analysis (2nd ed.). London: Starword.

Salt, B. (2006). Moving into pictures. London: Starword.

Simonton, D. K. (2002). Collaborative aesthetics in the feature film:
Cinematic components predicting the differential impact of 2,323 Oscarnominated movies. Empirical Studies of the Arts, 20, 115-125.

Simonton, D. K. (2007). Is bad art the opposite of good art? Positive versus negative cinematic assessments of 877 feature films. Empirical Studies of the Arts, 25, 143-161.

Simonton, D. K. (2009). Cinematic success, aesthetics, and economics: An exploratory recursive model. Psychology of Aesthetics, Creativity, and the Arts, 3, 128-138.

Smith, T. J. (2006). An attentional theory of continuity editing. Ph. D. thesis, University of Edinburgh. Retrieved from http://homepages.inf .Ed.ac.uk/s9732397/publications/smith_ATOCE_2006.pdf

Smith, T. J., \& Henderson, J. M. (2008). Edit blindness: The relationship between attention and global change blindness in dynamic scenes. Journal of Eye Movement Research, 2, 1-17.

Storey, J. (Ed.). (2009). Cultural theory and popular culture (4th ed.). London: Longman.

Thompson, K. (1999). Storytelling in the new Hollywood. Cambridge, MA: Harvard.

Thornton, T. L., \& Gilden, D. L. (2005). Provenance of correlations in psychological data. Psychonomic Bulletin \& Review, 12, 409-441.

Tversky, T., \& Geisler, W. (2008). Spatiotemporal statistics of motion through natural environments [Abstract]. Journal of Vision, 8, 1045. Retrieved from http://journalofvision.org/8/6/1045/, doi:10.1167/ 8.6.1045

Van Orden, G. C., Holden, J. G., \& Turvey, M. T. (2003). Selforganization of cognitive performance. Journal of Experimental Psychology: General, 152, 331-350.

Received March 12, 2010

Revision received July 6, 2010

Accepted July 7, 2010

\section{Showcase your work in APA's newest database. PsycTESTS}

Make your tests available to other researchers and students; get wider recognition for your work.

"PSycTESTS is going to be an outstanding resource for psychology," said Ronald F. Levant, PhD. "I was among the first to provide some of my tests and was happy to do so. They will be available for others to use - and will relieve me of the administrative tasks of providing them to individuals."

Visit http://www.apa.org/pubs/databases/psyctests/call-for-tests.aspx to learn more about PsycTESTS and how you can participate.

Questions? Call 1-800-374-2722 or write to tests@apa.org. Not since PsycARTICLES has a database been so eagerly anticipated! 